\title{
REVISITING THE EFFECTS OF SOCIOCULTURAL CONTEXT AND DISCIPLINES ON THE USE OF HEDGES IN RESEARCH ARTICLES
}

\author{
I Nyoman Suka Sanjaya \\ Politeknik Negeri Bali, Indonesia \\ suka.sanjaya@gmail.com
}

First draft received: 24 March 2015

Final draft received: 25 June 2015

\begin{abstract}
This study examines whether sociocultural context and discipline substantially affect usage of hedges in research articles. The corpus for the study consists of 104 research articles from two languages (English and Indonesian) with the disciplines of applied linguistics and chemistry. The analysis reveals that there is a statistically significant effect of sociocultural context in research articles from applied linguistics only. Interaction effect between sociocultural context and discipline is also observed. However, there is no statistically significant effect of the disciplines. It seems that both factors are not the major factors influencing usage of hedges in research articles. One intrapersonal factor, namely the cultural models embraced by the individual authors in regard to hedging usage, is proposed as a significant factor which determines the degree of uncertainty of research articles.
\end{abstract}

Keywords: hedges, academic written discourse, effect of sociocultural context

Traditionally viewed as an impersonal, faceless representation of absolute truth, research article writing has now come to be seen as the writer's act of making rhetorical appeal to the reader in an attempt to achieve persuasion. The writer's seeking endorsement of their contribution can be considered as an indication that academic knowledge is socially constructed and is constituted by the disciplinary discourse.

It is true that the extent to which the achievement of readers' endorsement is successful largely depends on the quality of the propositional content presented. However, presentation of ideas in writing requires more than quality proposition (Flowerdew, 2000). Kaplan (2005) submits that successful conveyance of message requires, among other things, knowledge of available genres and their linguistic resources. The writer's effective and/or strategic deployment of linguistic resources has been found to play a significant role in such knowledge ratification (Crismore and Farnsworth, 1989). Hedges (i.e. expressions of tentativeness and probability, such as may and perhaps) in particular, are linguistic resources which have been proved rhetorically powerful in persuading the readers and in influencing their attitudes towards the subject matter covered in the text (Crismore and Vande Kopple, 1997; Durik et al., 2007).

There are at least two reasons why linguistic devices such as perhaps, may, and it is possible can be considered as crucial in research articles. First, as the well-known scientist Albert Einstein stated, physical reality can only be perceived indirectly "by speculative means" (cited in Hyland, 1998b: 1). This implies that scientific statements cannot always be presented with full precision. Second, hedges can have a positive affective impact on readers (Crismore and Vande Kopple, 1997).

The rhetorical power inherent in hedges is, perhaps, what has kindled considerable interest among writing scholars. Studies designed to examine the use of hedges in research articles have largely examined English texts from different disciplinary fields (e.g. Abdi, 2002; Dahl, 2008; Gillaerts and Van de Velde, 2010; Hyland, 1996b; Hyland, 1998a; Hyland, 1998b; Kuhi and Behnam, 2011). Other studies compared how such interpersonal features were used in English and in other languages, such as Persian (Zarei and Mansoori, 2011), French and Norwegian (Marshman, 2008; Vold, 2006b), Spanish (Martín-Martín, 2008), Arabic (Sultan, 2011), German (Kreutz and Harres, 1997), and Bulgarian (Vassileva, 2001).

The studies of the deployment of hedges in English research articles have demonstrated the pervasiveness of such rhetorical devices not only in disciplines relying on verbal argumentation, such as sociology, but also in those fields which deal with so-called objective, measurable data, such as physics (e.g. Hyland, 2005b; Hyland, 2006; Hyland, 2008). This suggests that hedges play a significant role and constitute central pragmatic features in the process of engaging, influencing and persuading readers to assent to the writer's claims.

However, one of the unsettled issues regarding the use of hedges in research articles revolves around the degree of influence of the sociocultural context in which the articles are written (which is to some extent connected to the national culture of the authors) and discipline with which the scholars are affiliated. Furthermore, the considerable number of studies which have examined the use of hedges in research articles in English and other languages notwithstanding, it is quite surprising to note that, with the exception of $\mathrm{Hu}$ and Cao (2011), Yang (2013) and Itakura (2013), how these devices are used in research articles written in Asian languages has been left unexplored. In particular, studies of hedges deployed in research articles written in Indonesian are non-existent. 
As a corollary, very little is so far known about the use of these interpersonal devices in research articles written in these languages.

The purpose of the present study was to explore the degree of influence of the factors sociocultural context and discipline on the use of hedges in research articles. To be more specific, it was designed to examine whether the frequencies at which hedges were deployed in English and Indonesian research articles from the disciplines of applied linguistics and chemistry were significantly different from each other. These would provide information about whether sociocultural context and discipline largely influence, or constitute the sole factors determining, the use of hedges in research articles. The term 'sociocultural context' was operationally defined in this study as the social and cultural milieu in which research articles are produced.

Cross-cultural studies into scholarly writing practices, such as the one reported on here, are important for at least two reasons. On the theoretical level, the present study makes a significant contribution to the literature of academic writing, especially research article writing. That is, the findings of the present study contribute to avoiding what van Dijk (1994: 276) calls "scholarly and cultural chauvinism which at the very least diminishes the relevance and generality of our findings [i.e. findings of the studies conducted in dominant countries such as the U.S.]." The availability of research findings on academic writing in languages other than English will serve as a test case for the existing theory (i.e. the theory generated from findings of research into English academic writing). Such findings will further our understanding of academic writing theory, accordingly. The other significant feature of the present study is concerned with the practical benefits accrued by the Indonesian EAP (English for Academic Purposes) students and scholars. The availability of information about the rhetorical similarities and differences between English and Indonesian research articles enables the EAP practitioners in Indonesia to raise their students' and scholars' awareness of what makes acceptable rhetorical practices in the languages. Such awareness may promote their (i.e. students and scholars) negotiating capability in academic written discourse, which eventually can enhance the chances for successful publication.

The rest of the paper is structured as follows. The following section is concerned with corpus construction and identification of hedges, as well as data analysis. In the subsequent section, the findings of the study are presented, followed by a section in which I argue that the factors sociocultural context and discipline do not constitute the sole determinant factors influencing usage of hedges in research articles. A proposal of what affects usage of hedges in research articles is also presented in this latter section. Finally, in the concluding section, I suggest some directions for future studies on usage of hedges in research articles.

\section{METHOD}

Corpus

The corpus used for the present study was generated from 104 research articles (26 English applied linguistics articles, 26 Indonesian applied linguistics articles, 26 English chemistry articles, and 26 Indonesian chemistry articles). The corpus size was determined on the basis of

Table 1. Corpus size (in words)

\begin{tabular}{lccc}
\hline \multirow{2}{*}{ Language } & \multicolumn{2}{c}{ Field } & \multirow{2}{*}{ Total } \\
\cline { 2 - 3 } English & Applied Linguistics & Chemistry & 268,200 \\
Indonesian & 177,322 & 90,878 & 139,648 \\
Total & 105,246 & 34,402 & 407,848 \\
\hline
\end{tabular}

the result of an a priori power analysis conducted. LarsonHall (2010: 104) defines power as "the probability of detecting a statistical result when there are in fact differences between groups or relationships between variables." The output obtained from the a priori power analysis showed that 102 research articles, 51 from each language, were needed. However, since two disciplines from each language were analyzed in the present study 52 articles were taken from each language. Thus, instead of 102 research articles, 104 made up the corpus of the study.

The 104 research articles were drawn from the collection of all research articles published between 2007 and 2010 in each of the disciplines written in each of the languages using simple random sampling technique. The following table provides information about the size of the entire corpus, as well as of the sub-corpora making up the entire corpus.

As can be seen from the above table, the size of the entire corpus analyzed in the present study was 407,848 words. Table 1 above also shows that overall the size of the English sub-corpus (i.e. the two disciplines combined) was almost twice the size of the Indonesian sub-corpus. In fact, in both disciplines the English scholars wrote much longer articles compared to the Indonesian scholars. The means $(\mathrm{M})$ and standard deviations (SD) of the lengths (in words) of the articles in the four sub-corpora used in the present study (not shown in Table 1 above) were as follows: English applied linguistics $(\mathrm{M}=6,820.08 ; \mathrm{SD}=1,070.53)$, Indonesian applied linguistics $(\mathrm{M}=4,047.42 ; \mathrm{SD}=1,105.29)$, 
English chemistry $(\mathrm{M}=3,495.31 ; \mathrm{SD}=1,367.73)$, and Indonesian chemistry $(\mathrm{M}=1,323.15 ; \mathrm{SD}=461.33)$.

The construction of the entire corpus for use in the present study was based on what Connor and Moreno (2005) refer to as "tertium comparationis," a concept which simply refers to the notion that "we compare elements that can in fact be compared" (154). In the present study, every attempt was made to ensure that the texts for corpora were comparable. First, the two major corpora (English and Indonesian corpora) were drawn from online journals published over the same year period (2007-2010). Second, the texts from the two languages had to be written by the native speakers of the respective languages, judged from the name of the author (or from the name of the first author in the case of multi-authored articles). It is to be noted that these two points of comparison (year of publication and author) were the only ones which could be implemented in the present study. It was not possible, for example, to use impact factor as another point of comparison since Indonesian journals, unlike English (international) journals, did not receive impact factor (see also below). Arguably, these two points of comparison, together with the strict control of the content of the articles within each discipline, were powerful enough to ensure the comparability of the corpora under comparison.

The journals from which the Indonesian research articles were drawn were monitored by the Indonesian Ministry of Education in terms of, among other things, language style (i.e. register), ensuring that they used standard Indonesian. They were peer-reviewed journals and published by top ranked universities in Indonesia. Moreover, they were nationally-accredited journals, meaning that they were distributed throughout Indonesia only.

The selection of the two journals as the target population in the English chemistry corpus was determined by the impact factor of the journals; only those with the highest impact factor were selected. Another requirement for the English chemistry journal selection was that the issues addressed in the two journals had to somehow match those addressed in the corresponding Indonesian journals. For the English applied linguistics corpus, however, the impact factor of the journals unfortunately could not serve as a selection criterion, since those journals with high impact factor were very subject-specific (e.g. Journal of Memory and Language, Brain and Language), and they addressed issues which obviously were not addressed by the Indonesian applied linguistics journals in the Indonesian corpus. Therefore, the only selection criteria applied in the selection of the journals was that the journals had to somehow address issues similar to those addressed in the corresponding Indonesian journals.

\section{Identification Method}

A combination of manual and computer-based searches was employed to identify hedges in the Indonesian corpus of 52 research articles. First, over $25 \%$ of the articles from each of the disciplines in this language (i.e. seven articles from applied linguistics and 7 from chemistry) were thoroughly read to identify the hedges used. Such 14 articles were randomly selected from the entire corpus of each discipline. Then, two independent lists of Indonesian linguistic items (hedges) were generated from this manual reading: Indonesian applied linguistics list and Indonesian chemistry list. Two lists of English hedges were also generated from the two disciplines using the same procedure. The four lists of lexicons mentioned above were subsequently used as the basis for the computer-based search in the rest of the respective corpora. The search was done with the help of the Advanced Search function in the Adobe Acrobat Professional XI program.

\section{Identification of hedges}

In the identification of hedges in the present study, the definition of hedge proposed by Hyland (1996a) was strictly adhered to: "A hedge is ... any linguistic means used to indicate either (a) a lack of complete commitment to the truth of a proposition, or (b) a desire not to express that commitment categorically" (251). Thus, the underlined linguistic devices in the following sentences satisfy this requirement to be considered as hedges, since they are employed by the authors to withhold complete commitment to the proposition presented.

(1) A possible explanation for the observed order of reactivity primary $>$ tertiary $>$ secondary $>$ amide is that the greater degree of steric hindrance presented by N-methyl substitutions acts to hinder absorption.

(2) Bahasa yang digunakan dalam komunikasi pada umumnya tidak bersifat monolitis, ...

('The language used in communication generally is not monolithic, ...')

Any hedge found in a sentence used by the author(s) to cite other authors' viewpoint was excluded from the analysis in the present study cf. Crompton, 1997). Typically, such sentence had the cited author as the grammatical subject, as in (3) or started with the citing phrase as in (4) below. When a hedging device was used in this way, it was very clear that the author(s) merely reported the tentative statement of the cited author, rather than stated their own viewpoint.

(3) Landerito and Wang (2005a) proposed that the branching structure of amylopectin may retain more phosphates in the crystalline region for phosphorylation.

(4) Menurut Chomsky dalam Dardjowidjoyo manusia mempunyai apa yang dia namakan faculties of the mind, yakni semacam kapling-kapling intelektual (abstrak) dalam benak otak mereka, ...

('According to Chomsky in Dardjowidjoyo human beings have what he terms faculties of mind, a kind of (abstract) intellectual modules in their brains, ...')

It is to be noted that not all hedges which were used in sentences containing one or more citations were discounted from the analysis of the present study. In many cases, it was fairly straightforward to determine 
that the hedges used indeed derived from the author(s), rather than the cited authors. Consider the following sentence:

(5) Typically, the kinetics of drug release from swellable matrices depends on the structural features of the hydrogel and the processes of hydration and swelling of the polymer carrier, with the gel layer formed around the glassy core being the main controlling factor (Michailova, Titeva, \& Kotsilkova, 2005; Michailova, Titeva, Kotsilkova, Krusteva, \& Minkov, 2001).

In (5) above, based on the two previous studies cited, the authors somewhat cautiously state, through the use of the adverb typically, the dependence of "the kinetics of drug release" on "the structural features of the hydrogel and the processes of hydration and swelling of the polymer carrier." A great deal of similar rhetorical practice is also observed in Indonesian corpora and English corpora.

When two epistemic markers were present in the same proposition (sentences (6) and (7) below), both were included in the count.

(6) ... it would seemingly be less bound by the need to achieve profitability.

(7) ... it may indicate the vocabulary size necessary to understand a text as well as to incidentally learn words in the text.

The use of the adverb seemingly in (6) and modal verb may in (7) above was intended by the writers to further mitigate the strength of the proposition presented.

The Indonesian modal verb dapat 'can', when used before dynamic verbs (i.e. verbs denoting action), is used to express possibility (epistemic meaning), ability (root meaning) and permission (deontic meaning). Alwi (1992) states that when dapat is used side by side with another epistemic marker, the modal verb loses its epistemic meaning, but the root meaning is retained (105), as in the sentence (8) below.

(8) Adanya protein dan enzim ini kemungkinan dapat mengikat air dari lingkungannya.

('The presence of the protein and enzyme perhaps can absorb water from its surrounding')

Even when dapat was used in a construction such as Dapat disimpulkan bahwa 'It can be concluded that' (where it was not used with another epistemic device), a construction which constitutes a prefabricated chunk in Indonesian research articles in both disciplines found usually in the conclusion section, it was still extremely difficult to determine whether dapat in such linguistic context was used epistemically or in its root meaning. In Dapat disimpulkan bahwa it is not clear whether the writer intends to conclude tentatively (i.e. using the modal as an epistemic marker) or he or she uses the modal

Table 2. Descriptive statistics

\begin{tabular}{llccc}
\hline Context & Discipline & Mean & SD & N \\
\hline English & Applied Ling. & 10.20 & 4.69 & 26 \\
& Chemistry & 8.31 & 3.32 & 26 \\
& Total & 9.25 & 4.14 & 52 \\
& & & & \\
Indonesian & Applied Ling. & 4.43 & 3.69 & 26 \\
& Chemistry & 6.48 & 4.24 & 26 \\
& Total & 5.46 & 4.07 & 52 \\
Total & & & & \\
& Applied Ling & 7.32 & 5.09 & 52 \\
& Chemistry & 7.40 & 3.88 & 52 \\
& Total & 7.36 & 4.51 & 104 \\
\hline
\end{tabular}

in its root meaning to mean 'From the above evidence, I am in a position to (be able to) conclude that' (which implies that the writer is quite confident in the validity of the conclusion drawn). For this very reason, dapat was not included in the analysis. It was also true of the English modal can. Therefore, it would not be unreasonable to assume that dapat and can may not be a reliable hedge. This might be the reason why Hyland (1995a) does not include can as a hedge in his list. Can was also excluded from the analysis.

\section{Data analysis}

The present study, to reiterate, examined the effects of sociocultural context and discipline on the frequency of use of hedges in research articles. Therefore, the independent variables of the study were sociocultural context and discipline, each with two levels (English and Indonesian for the independent variable sociocultural context; applied linguistics and chemistry for the independent variable discipline), while the dependent variable was hedging usage. Given the nature of the study, the data were analyzed using two-way (2X2) factorial analysis of variance (ANOVA). All analyzes were conducted with the help of a statistical software, namely Statistical Package for Social Sciences (SPSS) program version 20.

\section{RESULTS AND DISCUSSION}

Table 2 below shows the frequency of use of hedges per 1,000 words in research articles from the two disciplines (applied linguistics and chemistry) in the two languages 
(English and Indonesian).

As can be seen from Table 2 above, overall (disciplines combined) the English research articles contained hedges at a much higher frequency than the
Indonesian research articles. It is also immediately apparent from the above table that hedges were more frequently used in both disciplines in English, although the difference between the English chemistry and

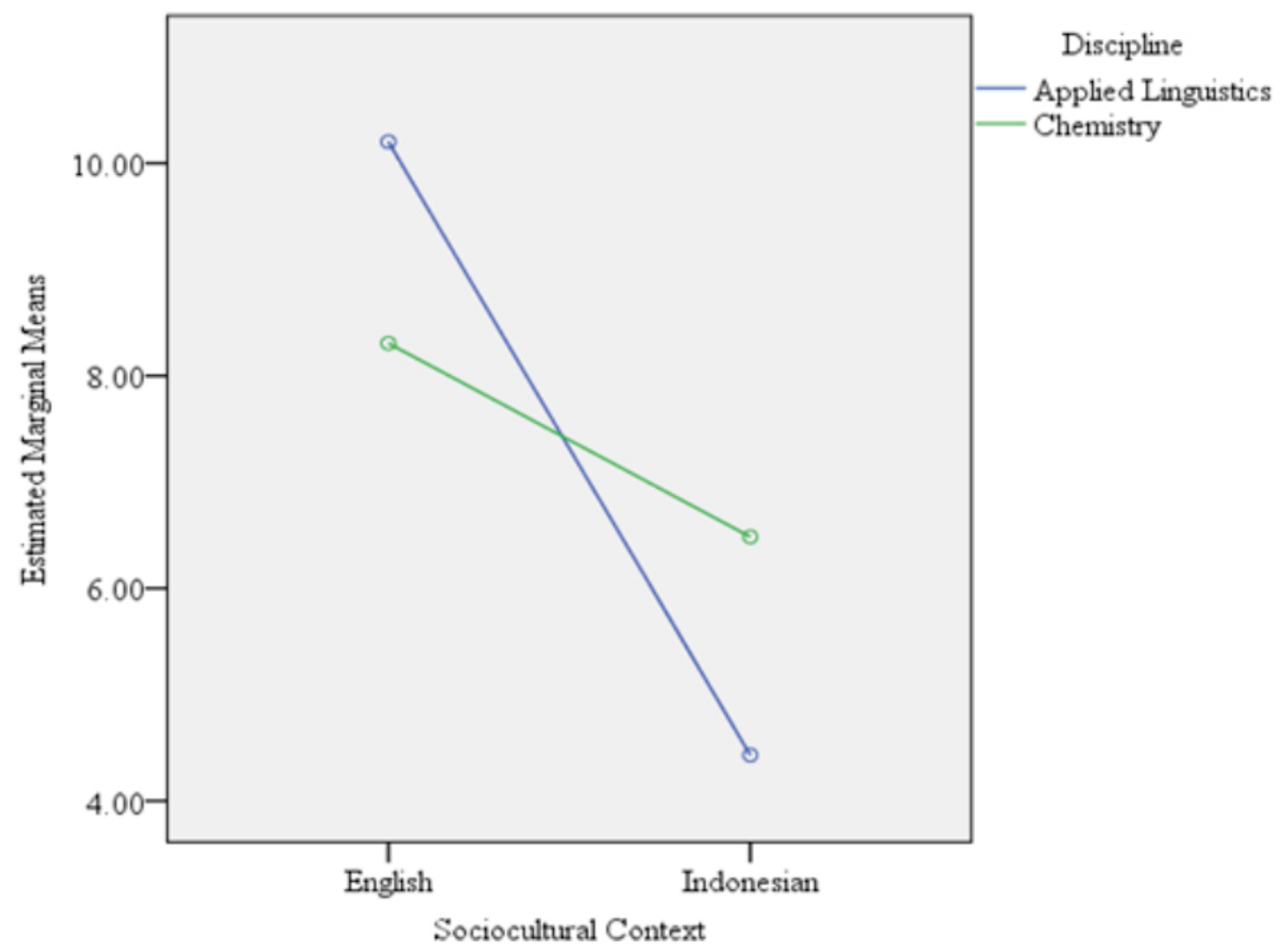

Figure 1. Interaction effects

Indonesian chemistry was smaller compared to that between the English applied linguistics and Indonesian applied linguistics. Indonesian research articles from both disciplines showed greater variability in terms of usage of hedges, compared to English ones. This was indicated by the size of standard deviation relative to the mean: Indonesian research articles, Mean $=5.46, \mathrm{SD}=$ 4.07 versus English research articles, Mean $=9.25, \mathrm{SD}=$ 4.14. Finally, the within-discipline comparison shown in the above table revealed that hedges were used across the two disciplines at relatively comparable frequencies.

The analysis revealed a statistically significant main effect of sociocultural context on the frequency of use of hedges in research articles, $F(1,100)=23.21, p<0.05, \eta^{2}$ $=0.19$. There was also a statistically significant interaction effect between sociocultural context and discipline on the frequency of use of hedges in research articles, $F(1,100)=6.28, p<0.05, \dot{\eta}^{2}=0.06$. However, the effect of discipline was found to be statistically nonsignificant, $F(1.100)=0.10, p>0.05, \eta^{2}=0.00$.

It is to be noted that the effect of sociocultural context on the use of hedges was not similar across the two disciplines (see Figure 1 below). The effect of sociocultural context on the use of hedges in research articles was greater in applied linguistics than in chemistry. In fact, the simple effects analysis conducted revealed that while such effect was statistically significant in the former discipline, $F(1,51)=27.08, p<$ 0.05 , it was statistically non-significant in the latter, $F(1$, $51)=2.70, p>0.05$. Also revealed by the simple effects analysis was that there was a statistically non-significant effect of discipline on the use of hedges in both languages: English, $F(1,51)=2.37, p>0.05$ and Indonesian $F(1,51)=2.78, p>0.05$.

The aim of the study was to examine whether sociocultural context and discipline constituted the significant determinant factors influencing the rhetorical features of research articles, more particularly usage of hedges. The study has found that sociocultural context had a statistically significant effect on the use of hedges only in research articles from applied linguistics, but not from chemistry. This suggests that sociocultural context might not serve as a significant, let alone the only, determinant factor influencing the use of hedges in research articles. This was further indicated by the small effect size, which was 0.19 , indicating that the difference 
in the use of hedges in research articles from the two disciplines due to sociocultural context accounted for only $19 \%$ of the overall variability. It was also found that sociocultural context and discipline interacted to influence the use of hedges in research articles, although the effect size could be considered to be negligible, which was 0.06 . This means that the difference in the use of hedges due to the interaction between sociocultural context and discipline accounted for only $6 \%$ of the total variability. This small effect size was largely due to the absence of a statistically significant effect of discipline on the use of hedges in any of the two languages. Taken together, as indicated by the statistical model generated from the data, the difference due to the two variables of concern in the present study (i.e. sociocultural context and discipline) accounted for only $23 \%$ of the overall variability.

It seems that non-English speaking scholars in the field of (applied) linguistics are more assertive in their presentation of claims than their English disciplinary colleagues. Consistent with the finding of the present study, the finding of the $\mathrm{Hu}$ and Cao (2011) study also revealed that applied linguistics research article abstracts written in English contained significantly more hedges than those written in Chinese. Vassileva (2001) also showed that English linguistics research articles contained more hedges than Bulgarian linguistics research articles.

The findings of the present study, as far as research articles from applied linguistics are concerned, substantiate Hyland's (2011, p. 181) contention that "compared with many languages, English academic writing tends to be more cautious in making claims, with considerable use of mitigation and hedging." This does not necessarily mean that research articles written in English are always more cautious in making claims than those written in any other language. Recall that in the present study there was no significant difference in the use of hedges between chemistry research articles in English and those written in Indonesian. Vold (2006b) also found that research articles written in English and those written in Norwegian were comparable in terms of their frequency of use of hedges. Likewise, Sultan's (2011) study also found that Arabic linguistics research articles contained more hedges than English articles.

It is interesting to note that when there is a statistically significant difference in usage of hedges observed between two groups of scholars writing in different languages the researchers' default explanation has been that those scholars are constrained by the sociocultural conventions of the society within which they reside. Hu and Cao (2011) and Yang (2013), for example, claimed that the use of hedges by Chinese scholars was a function of their Chinese national culture. Moreover, such culture-related explanation quite often made reference to the three cultural dimensions proposed by Hofstede et al. (2010), namely power distance, individualism and uncertainty avoidance. One of the findings of the present study did not support such culturebased explanation. Despite the fact that, from the perspectives of the power distance and individualism/ collectivism, English and Indonesian cultures are enormously different from each other (see Hofstede et al., 2010), English and Indonesian scholars from chemistry used hedges at comparable rates.

If we look at the two groups of countries (Indonesia and English-speaking countries) from which the authors whose research articles were analyzed in the present study in terms of the cultural dimension of uncertainty avoidance, the idea that sociocultural context is the significant determinant (let alone sole determinant) for rhetorical features of research articles can further be undermined as there is essentially no difference between the two groups of national cultures. Uncertainty avoidance refers to "the extent to which the members of a culture feel threatened by ambiguous or unknown situations" (Hofstede et al., 2010: 191, emphasis in original). The uncertainty avoidance index for Indonesia is 48 , whereas the indexes for the English-speaking countries range from 35 and 51. Since the two groups of countries have comparable uncertainty avoidance indexes, suggesting that members of the English culture "feel threatened by ambiguous or unknown situations" to the same extent that members of Indonesian culture do, we should expect that the presence of markers of uncertainty (i.e. hedges) in research articles written in the two languages (English and Indonesian) should also be comparable in terms of their frequency. In other words, there should be no statistically significant difference between the two sets of research articles in terms of frequency of use of hedges. Unfortunately, this expectation was not fully supported by the findings of the present study. As can be seen earlier in the Results section, although there was no statistically significant difference between English and Indonesian research articles from chemistry, the difference between the two sets of applied linguistics research articles was statistically significant. Indeed, the two disciplinary groups of scholars (applied linguists and chemists) in both languages were not statistically significantly different from each other in terms of frequency of use of hedges in their research articles, the finding which might be in support of the idea that sociocultural context determines usage of hedges in research articles. However, this latter finding goes against the argument that discipline determines usage of hedges in research articles. We will return to this point later in this paper.

It should be borne in mind that I am not arguing that the idea that rhetorical features of research articles (in particular, usage of hedges) are determined by the cultural characteristics of the context to which the writer belongs is inherently suspect and, accordingly, presumptively invalid. Cultural characteristics might affect rhetorical features. However, it is just that the effect is not large enough, or in other words there are some other factors which might also determine the rhetorical features of research articles. To make my argument clear, the findings of the present study did not support the idea that sociocultural context is a significant, (let alone the only) determinant factor which influences the rate of use of 
hedges in research articles, the idea which has been advanced by previous researchers.

According to Hyland (2006), the fundamental ontological difference between hard and soft knowledge domains has differing rhetorical consequences in research articles from the two knowledge domains. However, the findings from the present study did not fully support Hyland's (2006) claim. The comparative analysis of frequency of use of hedges by English and Indonesian scholars from the same discipline revealed that the two groups of scholars did not always adhere to the same rhetorical practice, suggesting that affiliation of the scholars with a particular discipline does not seem to always constrain the rhetorical features of their research articles, especially their use of hedges, although for chemistry scholars it seemed to be the case. It is to be borne in mind that the present study was not the only study which produced findings which were in disagreement with Hyland's argument. Vold (2006a) also reported that scholars from linguistics and medicine used hedges at significantly comparable rates.

The intrapersonal factor which might influence the use of hedges in research articles seems to be the cultural models associated with the use of such rhetorical features. The fact that Indonesian applied linguistics scholars were more assertive than English applied linguistics scholars reflected differing group cultural models adopted by the two groups of scholars. Cultural models are informal belief systems held by an individual used to help the individual to carry on the business of his or her living (Gee, 2012). For our present concern, it is the belief system which underlies the individual language use. For Indonesian applied linguistics scholars, generally speaking, research articles should carry authoritative tone, which represents the absolute authority of the writers which is not supposed to be challenged by the readers. It might be no exaggeration to say that research article writers in Indonesia, by virtue of their status as college professors, are highly regarded as scientific knowledge-making agents. As knowledgemaking agents, it might be taken for granted that whatever they present in their research articles must be true. It is this belief shared by the majority, if not all, people in Indonesia which might motivate research writers to be overly confident in their knowledge presentation.

The rhetorical patterning of research article introduction written in Indonesian provides telling evidence that the expertise of a researcher (and the absolute authority which comes with it) is not supposed to be questioned. In an analysis of 63 Indonesian research article introductions in three hard sciences (agriculture, biology and medicine) in terms of their rhetorical structure using Swales (2004) CARS (create a research space) model, Adnan (2008) showed that none was critical of a previous study or researcher. In other words, no researcher explicitly stated the limitations of previous studies.

It is to be borne in mind that not all Indonesian applied linguists shared the above belief. In fact, the degree of heterogeneity in terms of usage of hedges among this Indonesian group of scholars was quite high (see Table 2 above); on average, an Indonesian applied linguist used 4.43 hedges per 1,000 words and, at the same time, on average an Indonesian applied linguist deviated from this norm by 3.69 hedges per 1,000 words. This implies that some Indonesian applied linguists used hedges in their research articles at lower frequency rates than the average rate, and such rhetorical behavior was influenced by the belief system (i.e. cultural model) they embraced, the belief system which might be similar to that espoused by the majority of their English disciplinary colleagues.

English applied linguistics scholars in the present study, by contrast, did not seem to see themselves as being endowed with absolute authority, and hence they, generally speaking, did not operate within the same cultural models as the majority of Indonesian scholars did. Granted, English scholars are also perceived as experts in their field, but such status is quite different from the status as experts ascribed to their Indonesian colleagues; the difference lies in its vulnerability to criticisms. Analysis of any English research article introduction will provide solid evidence which suggests that the expertise of English scholars is susceptible to criticism. When a writer attempts to fill a knowledge gap, he or she typically argues that what has been done by previous researchers is limited, which is clearly a negative evaluation geared towards those previous researchers (Swales, 1990). This might trigger the more frequent use of hedges in English applied linguistics research articles, compared with Indonesian applied linguistics research articles. Like the Indonesian applied linguists, the English applied linguists, too, were not uniform in terms of their rate of usage of hedges in their research articles, although the degree of heterogeneity among the English applied linguists was lower compared to that among the Indonesian applied linguists (see Table 2). Thus, some English applied linguists used hedges at lower rates than the average rate, the rhetorical behavior similar to that of the average Indonesian applied linguists (i.e. writing more assertive).

The above explanation might also hold true of the finding from comparative analysis between the English chemistry research articles and Indonesian chemistry articles. The fact that both groups of research articles contained identical amount of hedges indicates that English chemistry scholars adopted cultural models which were, to some extent, similar to those adopted by their Indonesian disciplinary colleagues.

It is to be noted that the rhetorical behavior of a scholar could change as a result of his or her prior encounter with different linguistic experience(see Hoey, 2005). But why does a scholar take the trouble to shift from one rhetorical behavior to another? To put it another way, why does a scholar decide to deviate from the typical rhetorical behavior? The answer to this question seems to be related to their changing personal beliefs (i.e. cultural models) about what constitutes effective persuasion. In other words, owing to the unstable nature 
of cultural models (Gee, 2012; 97), the cultural models to which the scholar has previously been exposed (i.e. the ones underlying his or her previous rhetorical behavior) has now been replaced by a new set of cultural models, perhaps because the previous cultural models are now perceived by the scholar in question as no longer appropriate. This might explain why some Indonesian scholars behaved rhetorically more like English scholars, and English scholars behaved rhetorically more like Indonesian scholars, in terms of usage of hedges. For the Indonesian scholars who deviated rhetorically from their Indonesian colleagues, whose rhetorical behavior converged with that of the English scholars (i.e. those Indonesian scholars whose writing was largely cautious), it is probable that they no longer shared the same cultural models with other Indonesian scholars (i.e. those scholars whose writing was overly authoritative), but rather they now operated within the cultural models valorized by English scholars. By the same token, those English scholars whose writing was more authoritative relative to the other English scholars' writing can be regarded as sharing the same cultural models as the Indonesian scholars.

One might argue that the rhetorical style of a scholar is influenced by his or her previous academic literacy experience. For example, a non-English speaking scholar who has been exposed to English research articles might display in his or her research articles written in the native language rhetorical features similar to English research articles. However, despite the fact that the scholar has extensively been exposed to a certain writing style, if such style does not sit well with his or her personal belief (i.e. cultural model) regarding what constitutes an appropriate persuasive style, it will not significantly influence the rhetorical characteristics of his or her style.

To summarize, the findings of the present study did not provide strong empirical support for the idea that the rhetorical characteristics of a research article are largely influenced by the two factors of sociocultural context and discipline. Rather, it is hypothesized that rhetorical characteristics, more particularly usage of hedges, of a research article might be significantly determined by the cultural models (regarding the use of hedges) espoused by the author.

\section{CONCLUSION}

The findings of the present study showed that sociocultural context could not affect usage of hedges in research articles from all disciplines: the effect of sociocultural context was apparent only in discipline belonging to soft knowledge domain. Moreover, the observed effect was relatively small, suggesting that sociocultural context, contrary to what other researchers claim, is not to be considered a major determinant factor which influences usage of hedges in research articles. The non-uniformity of the frequency of use of hedges among researchers within the same sociocultural context also provided an indication that sociocultural context was not the major, let alone the sole, factor which influences rhetorical features (more particularly, usage of hedges) of research articles.

The idea that discipline significantly determines the rhetorical features of research articles also did not find empirical support from the present study, as indicated by the finding that English scholars and Indonesian scholars from the same discipline did not use the rhetorical features under study (hedges) comparably frequently. The finding that the two disciplinary groups of scholars writing within the same sociocultural context used hedges at comparable rates also provided crucial empirical evidence that discipline is not a major factor influencing the use of hedges in research articles.

That being said, there are other factors which might more strongly contribute to the degree of uncertainty of claims presented in research articles. In this paper, one of such factors is proposed, namely cultural models held by writers. This explanation should be considered as highly tentative, and hence further studies need to be carried out to validate it. Needless to say, future studies examining whether cultural models held by authors influence usage of hedges in their research articles will not benefit from heavy reliance on corpus-based method. That is, it might be more beneficial if the quantitative data are supplemented by data gathered from qualitative method, such as interviews. However, care needs to be taken when considering interviews as the supplementary methodological technique in gathering data, so as not to produce conflicting findings. Previous studies (e.g. Harwood, 2006) have found that what writers report during the interview about their rhetorical behavior is contradictory to what they actually practice in their writing.

\section{REFERENCES}

Abdi, R. (2002). Interpersonal metadiscourse: An indicator of interaction and identity. Discourse Studies 4(2), pp. 139-145.

Adnan, Z. (2008). Discourse structure of Indonesian research article introductions in selected hard sciences. In: Burgess S and Martín-Martín P (eds) English as an Additional language in research publication and communication. Berlin, Germany: Peter Lang, pp. 39-63.

Alwi, H. (1992). Modalitas dalam Bahasa Indonesia (Modality in the Indonesian language), Yogyakarta, Indonesia: Kanisius.

Bucholtz M. (2003). Sociolinguistic nostalgia and the authentication of identity. Journal of Sociolinguistics 7(3), pp. 398-416.

Connor, UM \& Moreno AI. (2005). Tertium comparationis: A vital component in contrastive rhetoric research. In: Bruthiaux P, Atkinson D, Eggington WG, et al. (eds) Directions in applied linguistics: Essays in honor of Robert B. Kaplan. Clevedon: Multilingual Matters, pp. 153-164.

Crismore, A. \& Farnsworth R. (1989). Mr. Darwin and his readers: Exploring interpersonal metadiscourse as a dimension of ethos. Rhetoric 
Review 8(1), pp. 91-112.

Crismore, A. \& Vande Kopple WJ. (1997). The effects of hedges and gender on the attitudes of readers in the United States toward material in a science textbook. In: duszak A (ed) Culture and styles of academic discourse. Berlin: Mouton de Gruyter, 223-247.

Crompton P. (1997). Hedging in academic writing: Some theoretical problems. English for Specific Purposes 16(4), pp. 271-287.

Dahl, T. (2008). Contributing to the academic conversation: A study of new knowledge claims in economics and linguistics. Journal of Pragmatics 40, pp. 1184-1201.

Durik, AM, Britt MA, Reynolds R, et al. (2007). The effects of hedges in persuasive arguments: A nuanced analysis of language. Journal of Language and Social Psychology 27(3), pp. 217234.

Flowerdew, J. (2000) Discourse community, legitimate pheriperal participation, and the nonnativeEnglish-speaking scholar TESOL QUARTERLY 34(1), pp. 127-150.

Gee, JP. (2012). Social linguistics and literacies, New York: Routledge.

Gillaerts, P and Van de Velde F. (2010). Interactional metadiscourse in research article abstracts. Journal of English for Academic Purposes 9, pp. 128-139.

Harwood, N. (2006). (In)appropriate personal pronoun use in political science: A qualitative study and a proposed heuristic for future research. Written Communication 23(4), pp. 424-450.

Hoey, M. (2005). Lexical priming: A new theory of words and language, New York: Routledge.

Hofstede, G, Hofstede GJ \& Minkov, M. (2010). Cultures and organizations: Software of the mind. intercultural cooperation and its importance for survival, New York: McGraw Hill.

Hu, G. \& Cao F. (2011). Hedging and boosting in abstracts of applied linguistics articles: A comparative study of English- and Chinesemedium journals. Journal of Pragmatics 43, pp. 2795-2809.

Hyland, K. (1996a). Talking to the academy: Forms of hedging in science research articles. Written Communication 13 (2), pp. 251-281.

Hyland, K. (1996b). Writing without conviction? Hedging in science research articles. Applied Linguistics 17 (4), pp. 433-454.

Hyland, K. (1998a). Boosting, hedging and the negotiation of academic knowledge. Text 18(3), pp. 349-382.

Hyland, K. (1998b). Hedging in scientific research articles, Amsterdam/Philadelphia: John Benjamins.

Hyland, K. (2005a). Metadiscourse: Exploring interaction in writing, London: Continuum.

Hyland, K. (2005b). Stance and engagement: A model of interaction in academic discourse. Discourse
Studies 7(2), pp. 173-192

Hyland, K. (2006). Disciplinary differences: Language variation in academic discourses. In: Hyland $\mathrm{K}$ and Bondi $\mathrm{M}$ (eds) Academic discourse across disciplines. Berlin: Germany: Peter Lang, 16-45.

Hyland, K. (2008). Different strokes for different folks: Disciplinary variation in academic writing. In: Flǿttum K (ed) Language and discipline perspectives on academic discourse. Newcastle upon Tyne: Cambridge Scholars Publishing, 89108.

Hyland, K. (2011). Academic Discourse. In: Hyland K and Paltridge B (eds) The Continuum Companion to Discourse Analysis. London: Continuum, 171-184.

Hyland, K. (2012). Disciplinary Identities: Individuality and community in academic discourse, Cambridge: Cambridge University Press.

Itakura, H. (2013). Hedging praise in English and Japanese book reviews. Journal of Pragmatics 45, pp. 131-148.

Kaplan, R.B. (2005). Contrastive rhetoric. In: Hinkel E (ed) Handbook of research in second language teaching and learning. Mahwah, NJ: Lawrence Erlbaum, pp. 375-391.

Kreutz, H. and Harres A. (1997). Some observations on the distribution and function of hedging in German and English academic writing. In: Duszak A (ed) Culture and styles of academic discourse. Berlin: Mouton de Gruyter, 181-201.

Kuhi, D. \& Behnam B. (2011). Generic variations and metadiscourse use in the writing of applied linguists: A comparative study and preliminary framework. Written Communication 28(1), pp. 97-141.

Larson-Hall J. (2010). A guide to doing statistics in second language research using SPSS, New York: Routledge.

Marshman E. (2008). Expressions of uncertainty in candidate knowledge-rich contexts: A comparison in English and French specialized texts. Terminology 14(1), pp. 124-151.

Martín-Martín P. (2008) The mitigation of scientific claims in research papers: A comparative study. International Journal of English Studies 8(2), pp. 133-152.

Sultan, A.H.J. (2011). A contrastive study of metadiscourse in English and arabic linguistic research articles. ACTA LINGUISTICA 5(1), pp. 28-41.

Swales J.M. (1990). Genre analysis: English in academic and research settings, Cambridge: Cambridge University Press.

Swales J.M. (2004). Research genres: Explorations and applications, New York: Cambridge University Press.

van Dijk TA. (1994). Academic nationalism (Editorial). Discourse \& Society 5(3), pp. 275276. 
Vassileva I. (2001). Commitment and detachment in English and Bulgarian academic writing. English for Specific Purposes 20, pp. 83-102.

Vold E.T. (2006a). The choice and use of epistemic modality markers in linguistics and medical research articles. Academic discourse across disciplines. Berlin, Germany: Peter Lang, pp. 225-249.

Vold E.T. (2006b). Epistemic modality markers in research articles: A cross-linguistic and crossdisciplinary study. International Journal of Applied Linguistics 16(1), pp. 61-86.

Yang Y. (2013). Exploring linguistic and cultural variations in the use of hedges in English and Chinese scientific discourse. Journal of Pragmatics 50, pp. 23-36.

Zarei G.R. \& Mansoori S. (2011). A contrastive study on metadiscourse elements used in humanities vs. non humanities across Persian and English. English Language Teaching 4(1), pp. 42-50. 